\title{
EVALUATION OF SATELLITE BASED NEAR-REAL TIME PRECIPITATION ESTIMATION OVER URBAN AREA
}

\author{
Agilan $\mathbf{V}^{1}$, Umamahesh $\mathbf{N ~ V}^{2}$ \\ ${ }^{I}$ Research Scholar, Department of Civil Engineering, NIT Warangal \\ ${ }^{2}$ Professor, Department of Civil Engineering, NIT Warangal
}

\begin{abstract}
The flood damage potential in urban area is high and the accurate flood/rainfall forecasting will reduce the damage caused by urban flooding. For flood forecasting, there is a need for proper knowledge on time distribution of rainfall in real time basis and this can be achieved based on near real time satellite rainfall estimates. In this paper, the Tropical Rainfall Measuring Mission (TRMM) near real time rainfall product, TRMM-3B42 RT v7, is validated using Indian Meteorological Department (IMD) hourly gauge observation of Hyderabad city, India. 3-h cumulative rainfall is calculated from hourly observed rainfall and compared with TRMM 3-h rainfall estimates. Our results indicate that the TRMM-3B42 RT v7 gridded 3 hour precipitation is overestimating the rainfall intensity and it is underestimating high intensity $(>17.6 \mathrm{~mm} / 3-h)$ rainfall events. Further, the TRMM is mostly missing the small rainfall events having intensity less than $0.2 \mathrm{~mm} / 3-h$.
\end{abstract}

Keywords: Evaluation, High Intensity Rainfall, Near-Real Time, TRMM, Urban area. $* * *$

\section{INTRODUCTION}

The flood damage potential in urban area is high due to population and property concentration in relatively small areas. In recent years, the increasing intensities of rainfall contributed significantly in urban area flooding with other causes such as rapid urbanization. The accurate flood/rainfall forecasting will reduce the damage caused by urban flooding. For flood forecasting, there is a need for proper knowledge on time distribution of rainfall in real time basis and this can be achieved based on near real time satellite rainfall estimates such as Tropical Rainfall Measuring Mission (TRMM) - Real Time product (3B42 RT). The TRMM-3B42 (version 7) is a TRMM gridded data product and it is produced by the TRMM project at the National Aeronautics and Space Administration (Qin, et al., 2014). TRMM-3B42 is corrected by gauge observations in all four datasets. TRMM-3B42 RT is a near-real-time version of TRMM-3B42. But, the difference is that TRMM-3B42 RT is not adjusted by gauge observations. TRMM-3B42 RT is a merged rain product, derived using Geostationary IR data and Microwave observations (Huffman, et al., 2007; Gao \& Liu, 2013). The TRMM-3B42 products are developed in four stages: (1) the microwave precipitation estimates are calibrated and combined; (2) infrared precipitation estimates are created using the calibrated microwave precipitation; (3) the microwave and IR estimates are combined; and (4) rescaling to monthly data is applied (Qin, et al., 2014). The TRMM3B42 was corrected using Global Precipitation Climatology Centre (GPCC) and the data is available at 3 hours temporal resolution and at $0.25^{\circ} \mathrm{X} 0.25^{\circ}$ spatial resolution. Evaluation of this product's capability and accuracy is essential to apply satellite rainfall estimates for flood prediction. Therefore, a study has been conducted to validate Near Real Time High Resolution Satellite Precipitation Product i.e. TRMM 3B42 RT v7.

\section{STUDY AREA AND DATA USED}

\subsection{Study Area}

For this study, one of the Indian city Hyderabad is chosen as study area. The location map of the study area is shown in Fig. 1 and it is in Telangana state and lies between latitude of $17.25^{\circ} \mathrm{N}$ and $17.60^{\circ} \mathrm{N}$ and longitude of $78.20^{\circ} \mathrm{E}$ and $78.75^{\circ}$ E.

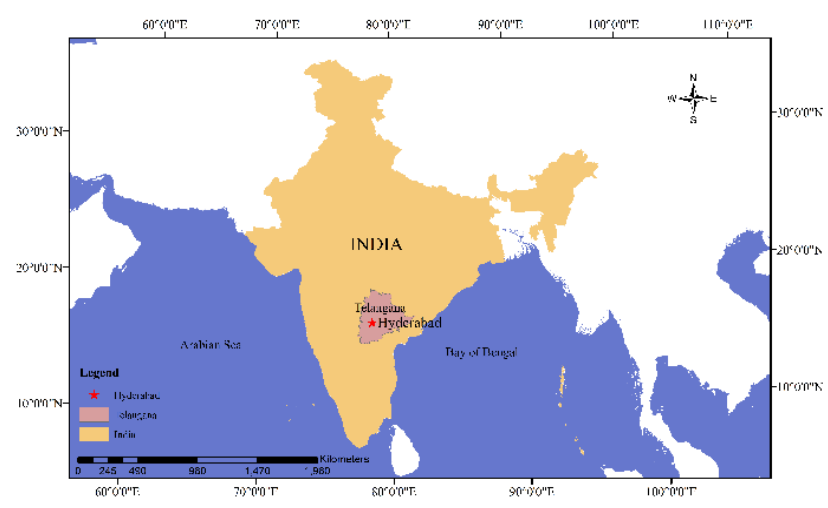

Fig. 1: Study area location map.

\subsection{Data Used}

The hourly observed rainfall data for the study area is procured from Indian Meteorological Department (IMD) for the period of 01-01-1998 to 31-12-2013(15 years) and 3 hour cumulative rainfall is calculated. For the observed rainfall location, which is center of Hyderabad city i.e. $78.46^{\circ} \mathrm{E}$ and $17.45^{\circ} \mathrm{N}$, the TRMM-3B42 RT v7 rainfall data product has been downloaded from TRMM TOVAS website (http://disc2.nascom.nasa.gov/Giovanni/tovas/TRMM_V7.3 B42.2.shtml : Accessed on 20-12-2014) for the same period 01-01-1998 to 31-12-2013(15 years). 


\section{METHODS}

To quantitatively evaluate TRMM estimates, the continuous verification statistics i.e. Mean Error (ME), Root Mean Square Error (RMSE) and correlation coefficients (r) are used and the formulas for these statistics are as follows (Qin, et al., 2014; Mishra, et al., 2010):

$$
\begin{aligned}
& M E=\frac{1}{n} \sum_{i=1}^{n}\left(E_{i}-O_{i}\right) \\
& R M S E=\sqrt{\frac{1}{n} \sum_{i=1}^{n}\left(E_{i}-O_{i}\right)^{2}} \\
& r=\frac{\sum_{i=1}^{n}\left(E_{i}-\overline{E_{i}}\right)\left(O_{i}-\overline{O_{i}}\right)}{\sqrt{\sum_{i=1}^{n}\left(E_{i}-\overline{E_{i}}\right)^{2}} \sqrt{\sum_{i=1}^{n}\left(O_{i}-\overline{O_{i}}\right)^{2}}}
\end{aligned}
$$

As we are interested towards predicting extreme rainfall events, thus the TRMM performance of estimating extreme rainfall events is also evaluated separately. For this, based on observed data, the probability $(\mathrm{P}(\mathrm{X} \geq x))$ that the intensity of rainfall on a given rainy 3 -h duration is equal or more than $x$ can be modelled by combining two exponential functions and it is given in equation (4).

$$
P(X \geq x)=0.5338 e^{-2.151 x}+0.5125 e^{-0.1726 x}
$$

For the model (equation (4)), the goodness of fit estimators, coefficient of determination $\left(\mathrm{R}^{2}\right)$, Sum of Square Error (SSE) and RMSE values are $0.99,1.44$ and 0.02 respectively. Based on the fitted model (equation (4)), the 0.05 and 0.02 probability rainfall intensity is calculated and corresponding event's prediction by TRMM is analyzed.

\section{RESULTS AND DISCUSSION}

The simple scatter plot between 3 hour cumulative TRMM estimate and 3 hour cumulative observed rainfall is shown in Fig. 2. The values of continuous verification statistics i.e. ME, RMSE and $\mathrm{r}$ are $0.02 \mathrm{~mm}, 2.40 \mathrm{~mm}$ and 0.44 respectively. Based on ME value it is noted that the TRMM3B42 RT is overestimating.

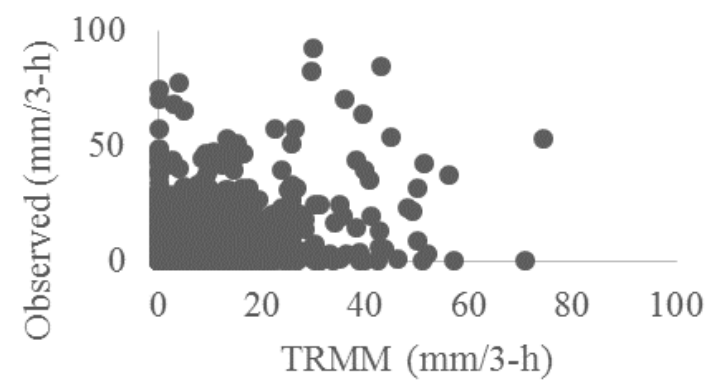

Fig. 2: Scatter plot between TRMM estimate and observed rainfall.
Overall, the TRMM-3B42 RT is overestimating. However, it is not the case in every event. The TRMM-3B42 RT is also underestimating. The difference between TRMM estimated and observed rainfall is revealed in Fig. 3 and it is noted that the number of positive differences are higher than the negative differences and it is evident that the TRMM is overestimating.

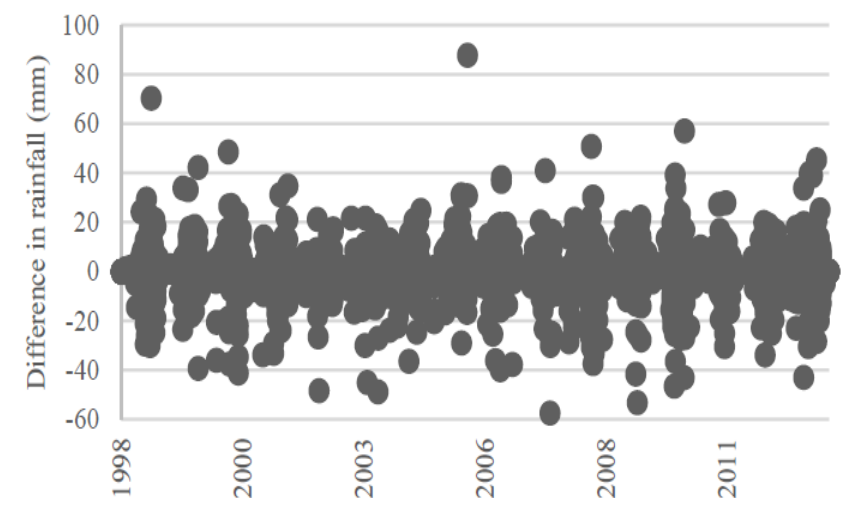

Fig. 3: Difference between TRMM estimate and observed.

Fig. 4 shows the comparison between actual and TRMM estimated rainfall events. In every year, the number event predicted by TRMM is less than the actual. This is because the TRMM is missing small rainfall events $(<0.2 \mathrm{~mm})$ and it can also be observed in Fig. 7. Therefore, every year, the number event predicted by TRMM is less than the actual.

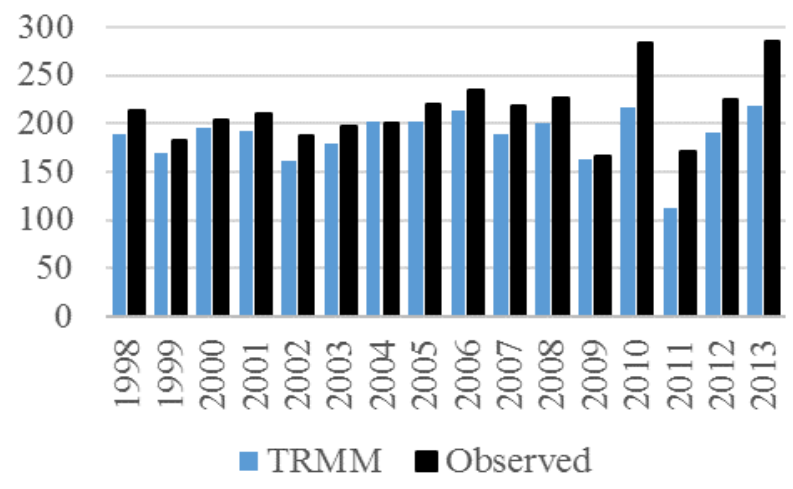

Fig. 4: Comparison between observed and TRMM estimated rainfall events.

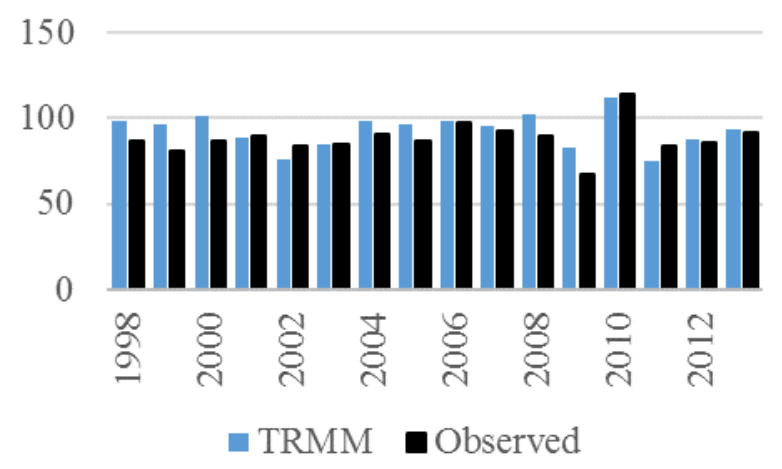

Fig. 5: Comparison between observed and TRMM estimated rainy days. 
But, Fig. 5 shows the comparison between observed and TRMM estimated rainy days and it is clearly visible that the number of rainy days are nearly equal or in some years the TRMM has high values than actual. It shows that the TRMM is also mispredicting the events and it is may be due to urban heat island. In addition, the rainfall-probability relationship curve is developed using both TRMM rainfall estimates and observed rainfall and revealed in Fig. 6. The rainfallprobability relationship shows that the TRMM is overestimating high probability $(>0.2$ rainfall events and underestimating low probability $(<0.08)$ events. The TRMM estimates and observed rainfall are nearly equal for medium probability $(0.1)$ events.

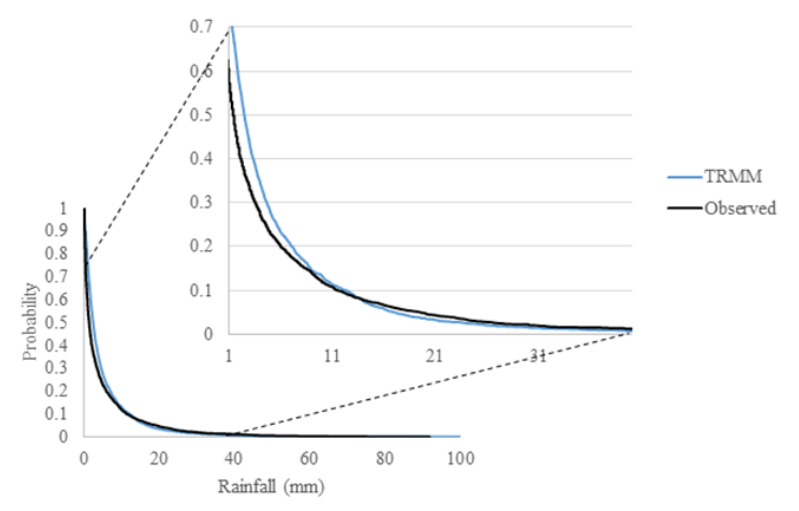

Fig. 6: Rainfall-probability relationship curve.

As discussed earlier, the TRMM is missing small rainfall events which are having intensity less than $0.2 \mathrm{~mm} / 3-\mathrm{h}$. In connection to that, the number of small rainfall events $(0.2$ $\mathrm{mm} / 3-\mathrm{h}$ ) in each year is analyzed. The comparison between TRMM estimated and observed count of small rainfall events is shown in Fig. 7. However it is insignificant, it is very clear that the TRMM is missing most of the small rainfall events. On an average, the TRMM is missing 32 small events per year.

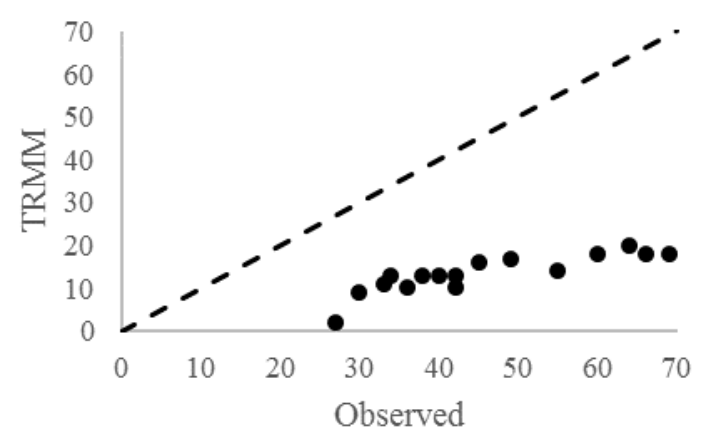

Fig. 7: Observed Vs TRMM small rainfall events count.

Further, the 0.05 and 0.02 probability rainfall intensity value is calculated using equation (4) and it is $17.6 \mathrm{~mm} / 3-\mathrm{h}$ and $28.38 \mathrm{~mm} / 3-\mathrm{h}$. The TRMM's ability to estimate extreme rainfall events whose probability of exceedance is less than 0.05 and 0.02 are analyzed. Fig. 8 shows the scatter plot between observed and TRMM estimated high intensity rainfall $(\mathrm{p}<0.05)$ events count and it is observed that the TRMM is underestimating extreme rainfall events. i.e. Even the observed rainfall is more than $17.6 \mathrm{~mm} / 3-\mathrm{h}$, in some cases, the TRMM is estimate is zero. Fig. 8 reveals the scatter plot between observed and TRMM estimated very high intensity rainfall $(\mathrm{p}<0.02)$ events count and it is observed that the TRMM is underestimating as well as overestimating very high intensity rainfall events.

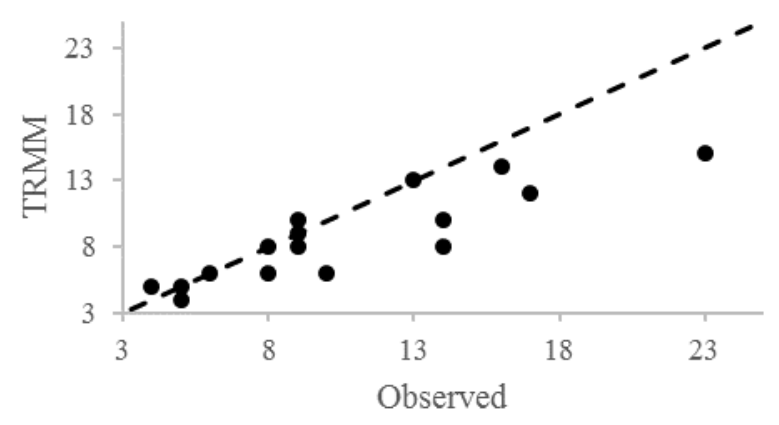

Fig. 8: Observed Vs TRMM- less than 0.05 probability rainfall events count.

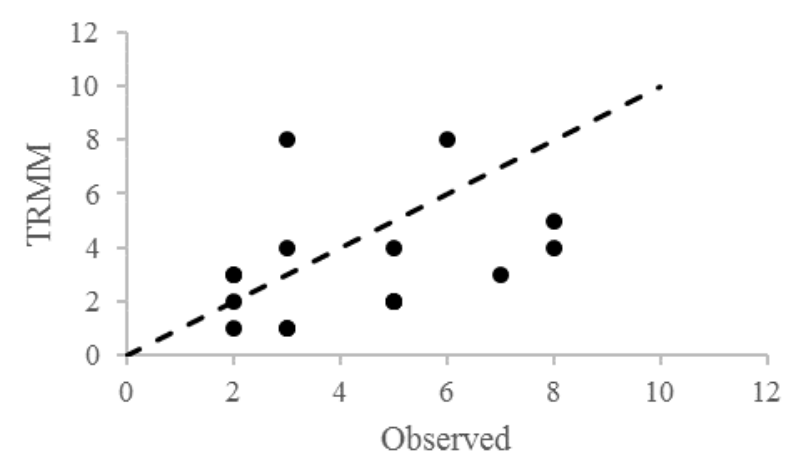

Fig. 9: Observed Vs TRMM- less than 0.02 probability rainfall events count.

\section{CONCLUSION}

From the study results, the following points have been concluded:

- Overall, the TRMM-3B42 RT v7 gridded 3 hour precipitation is overestimating the rainfall intensity.

- The TRMM-3B42 RT v7 is underestimating the rainfall events and it is because the TRMM-3B42 RT v7 is mostly missing small rainfall events having intensity less than $0.2 \mathrm{~mm} / 3$-h and the number of rainy days estimate is nearly equal to observed.

- $\quad$ Further, the TRMM-3B42 RT v7 is underestimating high intensity rainfall events and it is underestimating as well as overestimating very high intensity rainfall events.

\section{ACKNOWLEDGEMENTS}

This work is undertaken as part of ITRA, Media Lab Asia project entitled "Integrated Urban Flood Management in India: Technology Driven Solution". We also thank Indian Meteorological Department (IMD) for providing rainfall data. 


\section{REFERENCES}

[1] Gao, Y. C. \& Liu, M. F., 2013. Evaluation of highresolution satellite precipitation products using rain gauge observations over the Tibetan Plateau. Hydrol. Earth Syst. Sci., pp. 837-849.

[2] Huffman, G. J. et al., 2007. The TRMM Multisatellite Precipitation Analysis (TMPA): Quasi-Global, Multiyear, Combined-Sensor Precipitation Estimates at Fine Scales. Journal of Hydrometeorology, pp. 3855.

[3] Mishra, A., Gairola, R. M., Varma, A. K. \& Agarwal, V. K., 2010. Remote sensing of Precipitation over Indian land and oceanic regions by synergistic use of multi-satellite sensors. Journal of Geophysical Research, pp. D08106 1-12.

[4] Qin, Y. et al., 2014. Evaluation of Satellite Rainfall Estimates over the Chinese Mainland. Remote Sens., pp. 11649-11672. 